UNIVERSITY OF GOTHENBURG

SCHOOL OF BUSINESS, ECONOMICS AND LAW

WORKING PAPERS IN ECONOMICS

No 541

\title{
Conditional Cooperation and Disclosure in Developing Countries
}

\author{
Peter Martinsson \\ Nam Pham-Khanh \\ Clara Villegas-Palacio
}

September 2012

ISSN 1403-2473 (print)

ISSN 1403-2465 (online) 


\title{
Conditional Cooperation and Disclosure in Developing Countries*
}

\author{
Peter Martinsson ${ }^{\mathrm{a}}$ \\ University of Gothenburg, Sweden \\ Nam Pham-Khanh ${ }^{b}$ \\ University of Gothenburg, Sweden \\ Ho Chi Minh City University of Economics, Vietnam \\ Clara Villegas-Palacio ${ }^{\mathrm{C}}$ \\ University of Gothenburg, Sweden \\ Universidad Nacional de Colombia- Sede Medellín, Colombia
}

\begin{abstract}
Understanding the motivations behind people's voluntary contributions to public goods is crucial for the broader issues of economic and social development. By using the experimental design of Fischbacher et al. (2001), we investigate the distribution of contribution types in two developing countries with very high collectivism rating - Colombia and Vietnam - and compare our findings with those previously found in developed countries. We also investigate the effect of introducing disclosure of contribution on the distribution of contribution types and on the contribution itself. Overall, our experiments show that the distribution of contribution types remains unaffected by the disclosure of contributions and, on average, is similar both in the two countries and when compared with previous findings with the exception of proportion of free-riders.
\end{abstract}

JEL classification: C72; C92; H41.

Key words: Conditional cooperation; Disclosure; Experiment; Public Goods.

\footnotetext{
Acknowledgments: Financial support from the Swedish Research Council (Vetenskapsrådet), the Jan Wallander and Tom Hedelius Foundation, Formas through the program Human Cooperation to Manage Natural Resources (COMMONS), and Sida (the Swedish International Development Cooperation Agency) to the Environmental Economics Unit at the University of Gothenburg is gratefully acknowledged. We would like to thank Olof Johansson-Stenman, Fredrik Carlsson and Martin Kocher for helpful comments and suggestions. We are grateful to Lina María Berrouet and Nguyen Sy Phuc for excellent research assistance in Colombia and Vietnam.

a Department of Economics, University of Gothenburg, Gothenburg, Sweden; Ph +46 31786 52 55; e-mail: Peter.Martinsson@economics.gu.se.

${ }^{\mathrm{b}}$ Department of Economics, University of Gothenburg, Gothenburg, Sweden; Ph +46 3178647 59; e-mail: pham.khanh.nam@economics.gu.se.

${ }^{\mathrm{c}}$ Department of Geosciences and Environment. Engeneering Faculty, Universidad Nacional de Colombia- Sede Medellín. Ph +57 30139155 56; e-mail: civilleg@unal.edu.co. (Corresponding author)
} 


\section{Introduction}

Research on public goods has for a long time focused on the conditions under which individuals cooperate, and in recent decades public goods experiments have been used as the workhorse to better understand contributions to public goods (see overviews in e.g., Chaudhuri, 2011; Ledyard, 1995; Zelmer, 2003). One early insight from these experiments was that behind the veil of an average positive amount being contributed to a public good, individual contributions varied widely and included a large fraction of free-riders. To gain better insight into people's contribution behavior to public goods, but also to better understand the dynamics of contributions, it is important to investigate the distribution of different types of contributor in a population. One important contributor type that has been identified is the conditional cooperator, i.e., a subject who will contribute an amount that he or she thinks will be similar to the contributions of others. ${ }^{1}$

One approach to investigate conditional cooperation empirically is to explain contribution in the current period by comparing it with those from the previous period; for example Keser and Van Winden (2000) found a significant and positive relationship between these two components. Fischbacher et al. (2001) developed an alternative examination of types of contributor by using a public goods experiment based on the strategy method. In their experimental design, subjects are asked in an incentive-compatible way not only how much they would contribute to the public good as in a standard public goods experiment (i.e., unconditional contribution) but also how much they would contribute conditional on the average amount contributed by the other group members ranging from a zero contribution to the maximum amount (i.e., conditional contributions). Based on people's conditional contributions, free-riders are identified as subjects who contribute zero regardless of the contributions made by others, while conditional cooperators are those who increase their contributions as the average contributions made by others increases. In Fischbacher et al. (2001), free-riders and conditional cooperators are the two dominating types; on average conditional cooperators make up a larger proportion of the population than free-riders, but there are variations between locations (e.g., Fischbacher and Gächter, 2010; Herrmann and Thöni, 2009; Kocher et al., 2008; Thöni et al., 2009). In a follow-up paper, Fischbacher and Gächter (2010) show in a within-subject design that the types identified using the strategy method correspond to behavior in a standard multi-period public goods experiment where

\footnotetext{
${ }^{1}$ For an early discussion on this topic in psychological literature, see, e.g., Kelley and Stahelski (1970).
} 
only unconditional contributions are elicited, supporting the behavioral validity of the strategy method in this context.

The behavioral pattern of conditional cooperation can be explained by various kinds of motivations. Benabou and Tirole (2006) have categorized motivations into three main categories: intrinsic, extrinsic, and image. While intrinsic and extrinsic motivations focus on factors such as altruism and monetary rewards respectively, image motivation focuses on the fact that individuals derive utility from how other people perceive them (i.e., social approval), and from the way they perceive themselves (e.g. self-image). Thus, the model by Benabou and Tirole (2006) offers two explanations for conditional co-operations namely intrinsic (e.g., greed and prosociality) and image motivations. Conditional cooperation in a standard anonymous public goods experiment setting can be explained by intrinsic motivations and self-image from the model by Benabou and Tirole (2006). Previous empirical evidence suggests that introducing disclosure can enhance contribution to the provision of public goods (e.g., Ariely et al. 2009; Rege and Telle, 2004; Soetevent 2005). In a laboratory setting, Rege and Telle (2004) investigate the effect of disclosure in a one-shot public goods experiment where the subjects reveal their own contributions to the other group members. They find significantly higher contributions when contributions are disclosed. Thus, this indicates that the overall effect of the introduction of disclosure on changes in intrinsic (for example a negative effect through greed) and image (for example a positive effect through social approval) motivations resulted in a positive net effect on cooperative behavior. Noussair and Tucker (2007), however, find an insignificant effect of disclosure when using a design similar to Rege and Telle (2004), and in a multi-period public goods experiment with disclosure they find significantly lower contributions. It should be noted that the experiment by Noussair and Tucker (2007) used a multi-period setting, and thus there is a strategic motivation for cooperation in their case, which might affect behavior negatively through intrinsic and image motivations. The first objective of the present paper is to study the effect of disclosure of the contribution to the public good on contribution behavior and contribution type by using the innovative between-subject design by Fischbacher et al. (2001) combined with disclosure of contributions.

A recent development in public goods experiments is the investigation of behavioral differences and similarities across societies. Most of the knowledge from public goods experiments is based on multi-period experiments in Western Europe and the U.S. Herrmann et al. (2008) conduct a standard 10-period public goods experiment in 16 different locations 
worldwide including Western European countries, China, South Korea, Turkey, Australia, Saudi-Arabia, and the Yemen, and find differences in initial contribution between locations but a similar rate of decay in contributions over time. Gächter et al. (2010) present a more detailed analysis of the data in Herrmann et al. (2008) focusing on cooperation and culture. By using the definition of culture by Inglehart and Baker (2000) and Hofstede (2001), countries can be classified into different cultures. The largest cultures missing from the studies by Herrmann et al. (2008) are South East Asia, Africa and Latin America. In a decomposition analysis, Gächter et al. (2010) show that by and large, contributions in the standard public goods experiment are only determined by culture to a very small extent, but that group and individual behaviour have a much greater effect. However, the application of an experimental design, as suggested by Fischbacher et al. (2001), which allows for detailed classification of types of contributor, has to a much lesser extent been applied both generally and to different cultures worldwide (e.g., Fischbacher et al., 2001 in Switzerland; Fischbacher and Gächter, 2010 in Swizterland; Herrmann and Thöni, 2009 in Russia; Kocher et al., 2008 in Austria, the USA and Japan; Thöni et al., 2009 in Denmark). We conducted our public goods experiment in two locations where very few published public goods experiments have been conducted, i.e., in Vietnam in South Asia and in Colombia in Latin America, using the design by Fischbacher et al. (2001). ${ }^{2}$ On the dimension of collectivism versus individualism in the context of people's integration in groups, both Colombia and Vietnam have a very high collectivism rating (Hofstede, 2001). This is in contrast to, for example, the USA, which has one of the highest rating for individualism, and Switzerland (where several of the experiment by Fischbacher and colleagues were conducted), which also scores high for individualism. Our second objective in this paper is to investigate the distribution of contributor types in Vietnam in South East Asia and in Colombia in Latin America, using the design by Fischbacher et al. (2001).

Understanding about how disclosing contributions affects contribution patterns within and across cultures is limited in previous literature. Thus, by conducting the same public goods experiment both in Vietnam and in Colombia, we can not only compare the distribution of contributor types between these two countries but also compare the effects of disclosure on both contributions and contributor types across culture. Research evidence in cross-cultural psychology, sociology, and anthropology suggest that people in different cultures have

\footnotetext{
${ }^{3}$ At the time of the experiment, 1 USD=2,000 COP and 1 USD=17,500 VND. Two of this paper's authors are native speakers of Spanish and Vietnamese, respectively. The English instructions were translated into Spanish and Vietnamese and then back into English to check for translation accuracy.
} 
different perceptions and interpretations of the self, of others, and of the interdependence of the two (Markus and Kitayama, 1991). Many Asian cultures, like the Vietnamese, insist on the fundamental relatedness of individuals to each other and are characterized by an interdependent view of the self (Markus and Kitayama, 1991). Previous experimental research has documented very high, by western standards, levels of trust and cooperation amongst strangers in Vietnam (Carpenter et al., 2004) denoting the existence of social capital bridging. In Colombia, however, social capital is of the bonding type centering around family and small groups of friends and social capital bridging tends to be very scarce (Thoumi, 2009). It could be said that in Colombia there is an interdependent view of the self that is moderated by a highly selective attention to others, most characteristically family and friends, while in Vietnam there is an interdependent view of the self with a lower degree of selection. Subjects with an independent view of self should be motivated by those actions that allow expression of their inner attributes whereas people with an interdependent view of self should be motivated by actions that enhance their sense of connection to others (Markus and Kitayama, 1991). Since disclosure is in front of strangers, we would expect if anything Vietnamese to be more sensitive to strangers than Colombians explained by image motivation. However, since the degree of collectivism is already high in Vietnam and Colombia (Hofstede, 2001), there might be less effect of disclosure compared with other countries where disclosure has been tested.

The rest of the paper is organized as follows: Section 2 presents the experimental design and procedures, Section 3 contains the results, and finally, Section 4 offers some concluding remarks.

\section{Experimental design}

We used a linear public goods experiment based on the strategy method as developed by Fischbacher et al. (2001). Subject $i$ 's payoff in tokens from the public goods experiment is given by

$$
\pi_{i}=20-c_{i}+0.4 \sum_{j=1}^{4} c_{j}
$$

where $c_{\mathrm{i}}$ is the amount allocated to the public good by subject $i$. Each group consisted of four randomly matched subjects, where each subject was endowed with 20 tokens. Each token 
earned in the experiment corresponded to 750 COP (Colombian Pesos) in Colombia and 6000 VND (Vietnamese Dong) in Vietnam. We determined the exchange rate for the tokens in each country such that the average payoff of a subject would slightly exceed the average earning from a student's part-time job. ${ }^{3}$ The marginal per-capita return (MPCR) from the public good was set at 0.4. For a rational and selfish subject, it is obvious that any MPCR below one results in a dominant strategy to free-ride, i.e., to contribute zero to the public good. However, from a social perspective, it is optimal to contribute the whole endowment because MPCR*n $>1$, where $n$ is number of group members. Thus, an MPCR of 0.4 fulfills the requirement for a public good by creating a conflict between private and social optima.

Since our experiment was based on the experimental design by Fischbacher et al. (2001), we elicited both conditional and unconditional contributions to the public good. In the conditional contribution part, the strategy method was used, i.e., subjects were asked, in what is called the conditional contribution table, how much they would like to contribute to a public good conditional on all possible combinations of the average contribution levels (rounded to the nearest integer) of the other group members. In the unconditional part, subjects were asked how much they would like to contribute to a public good, replicating a standard one-shot public good experiment. In order to make each of the choices incentivecompatible, we randomly chose three subjects in each group and let their unconditional contributions count as their contributions to the public good. The payoff-relevant contribution for the fourth subject was based on his or her conditional contribution table, where the contributed amount corresponds to the amount stated conditional on the average unconditional contributions of the other three members. Finally, by adding the three unconditional contributions and the conditional contribution by the fourth member, the total contribution by the group to the public good could be calculated using equation (1). Afterwards, we also asked subjects about their beliefs regarding what others had contributed unconditionally. As in Gächter and Renner (2010), subjects were rewarded in tokens for accurate guesses.

The subjects were recruited from undergraduate students at Universidad Nacional de Colombia-Sede Medellín in Medellin, Colombia and at Nha Trang University in Nha Trang, Vietnam. Subjects were randomly selected from a list of people who registered in response to an e-mail invitation to participate in the experiment. Using the chi-square test, we cannot

\footnotetext{
${ }^{3}$ At the time of the experiment, 1 USD=2,000 COP and 1 USD=17,500 VND. Two of this paper's authors are native speakers of Spanish and Vietnamese, respectively. The English instructions were translated into Spanish and Vietnamese and then back into English to check for translation accuracy.
} 
reject the hypothesis of equal distribution of gender and degree of selfishness at the $5 \%$ significance level between the two treatments in each country.

We ran two treatments (with two sessions per treatment) in each country. In the nodisclosure treatment, neither the identity of subjects nor the contributions made by the subjects were revealed during or after the experiment. In the disclosure treatment, each subject's contribution and group membership were disclosed to everyone in the session once all contributions had been submitted. Up to the point of disclosure, there were no differences between the treatments except that the subjects in the disclosure treatment received information about the disclosure procedure in their instructions. At the time of disclosure, the four group members were asked to come together, one group at a time, and sit down on four chairs in front of the remaining twenty participants in the session. Once the four group members were seated, each subject was asked one at a time by using experimental identification numbers to stand up, whereby his or her payoff-relevant contribution to the public good was publicly announced by the experimenter. All subjects in the disclosure treatments knew about the disclosure procedures in advance since they were clearly described in the instructions for the experiment.

We disclose the income-relevant contribution instead of the individual's strategy in the contribution table mainly for two reasons. On the one hand, disclosing the income-relevant contribution of each participant means that our paper is in line with previous literature that has studied the effect of disclosure on contributions to a public good which ex-ante facilitates comparison with other papers that have studied the issue like Rege and Telle (2004) and Noussair and Tucker (2007). On the other hand, it is difficult to know if, and if so, how, disclosing their income-relevant contribution rather than their strategy affects subjects' behavior. In an interesting paper, Fischbacher and Gächter (2010) compare the strategy and the contribution methods in a standard multi-period public goods experiment. They find that people classified as conditional cooperators by the strategy method behave accordingly in the standard public goods experiment. In addition, similar findings were made for free-riders indicating the behavioral validity of the strategy method in public good experiments. To our knowledge, these are the only direct results on this topic. In a survey paper by Brandts and Charness (2011), they conclude that on average the strategy method and the direct response method result in consistent results. By and large, we do not a priori have any expectations that the effect will be in one direction or the other, rather we expect this choice not to have an effect based on above, but this will be a research question for the future. 
At the beginning of the experiment, instructions were handed out and read aloud to the subjects. The instructions included several examples and exercises and the subjects were allowed enough time to solve the exercises on their own. Once all participants had completed the exercises, the experimenter solved them in public. Any remaining questions that the subjects had were then answered in private. The subjects decided how much to contribute unconditionally to the public good, and filled in the contribution table where they indicated their contribution to the group account given the possible average contributions (rounded to the nearest integer) of the other three members of the group. After collecting the decision sheets, the participants were asked to state their beliefs regarding the total unconditional contribution levels of the other three participants to the public good account. Finally, the subjects completed a socio-economic questionnaire. The experimenter randomly selected, by using the identification numbers, one member in each group for whom the conditional contribution was the income-relevant decision and then calculated the amount to be paid to each subject. For the disclosure treatment, the contribution-revealing stage was conducted after the collection of the questionnaires. At the end of the experiment, all subjects were paid privately in cash (on average approximately 23,000 COP and 181,000 VND).

\section{Experimental results}

We use the conditional contribution tables to analyze the relationship between a subject's own conditional contribution and the average contribution of the other members in his or her group. In Figure 1, following Fischbacher et al. (2001), we plot the relationship between the average own conditional contribution (on the vertical axis) and the average contribution of the other members (on the horizontal axis). The overall picture is the same across locations and treatments, and shows that people contribute more when the average of others' contributions increases. The slope is less than one, which indicates imperfect conditional cooperation. Moreover, there is a positive average contribution to the public good when others give zero. This can be interpreted as altruism, and exists in both treatments for both countries. These patterns are all consistent with previous studies. 
Figure 1. Average own contribution level for each average contribution level of other group members.

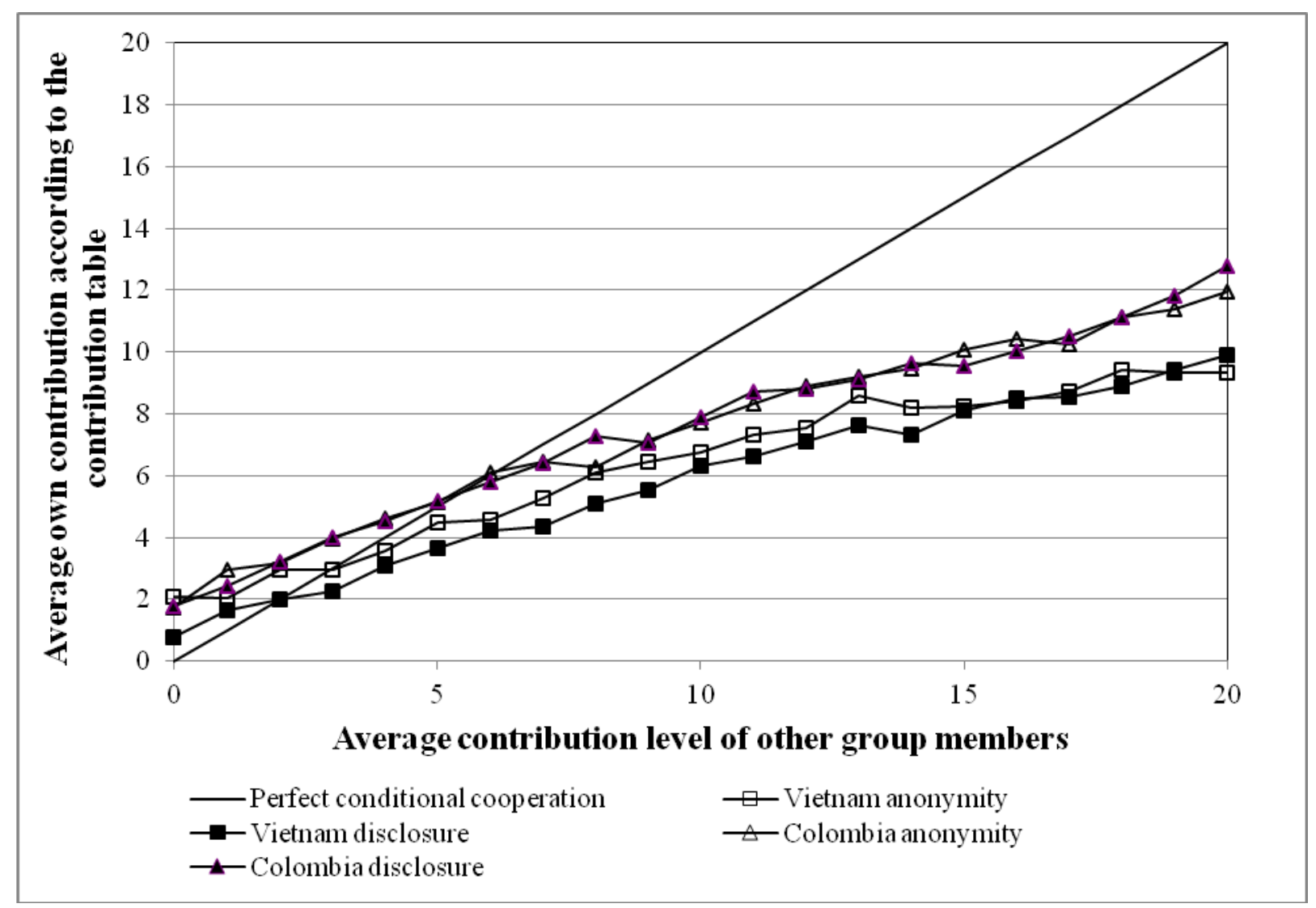

Based on the conditional contributions, we categorize subjects into different types of contributors, using the same classifications as in, e.g., Fischbacher et al. (2001) and Fischbacher and Gächter (2010). We classify a subject as a free-rider if his or her own contribution is zero for all possible average contributions of the other members, while a conditional cooperator is someone whose own conditional contribution increases weakly and monotonically with the average contribution of the other members. In addition, subjects are also classified as conditional cooperators if the relationship between their own average contributions and those of others is positive and significant at the $1 \%$ significance level based on the Spearman rank correlation coefficient. Hump-shaped contributors (triangle contributors) show weakly and monotonically increasing contributions (or increasing with a Spearman rank correlation coefficient at the $1 \%$ significance level) up to a certain level of the contributions of others, but beyond this level their conditional contributions decrease based on a reversed classification. The remaining subjects are categorized as others. 
Table 1 summarizes the distribution of contributors - free-riders, conditional cooperators, hump-shaped, and others - in our treatments and in previous studies. One focus of the paper is to investigate the effects of disclosure and compare them across countries. We begin by testing the null hypothesis of equal distribution of contribution types in the nodisclosure and disclosure treatments using a Fisher's exact test in each country. We can reject the null hypothesis at the $5 \%$ significance level in the Colombian experiment (p-value=0.04), but not in the Vietnamese experiment ( $\mathrm{p}$-value $=0.42$ ). Then we perform the pair-wise tests of equal proportion of types between treatments in each country. The result of the Fisher's exact test only shows that the proportion of the "other" type is significantly different at the $5 \%$ level in Colombia. The main effect of the disclosure seems to be that the proportion of the "other" type decreases, which might be explained by the idea that subjects consider their contributions more carefully when they are to be revealed in public.

In Table 1, we also present the proportion of subjects classified into the four categories used in Fischbacher et al. (2001) (conducted in Switzerland), Thöni et al. (2009) (in Denmark), Herrmann and Thöni (2009) (in Russia), and Kocher et al. (2008) (in the U.S., Austria, and Japan). When we compare the no-disclosure treatments, we notice similar distributions between Colombia and Vietnam. However, when compared with previously conducted experiments, there are fewer free-riders in Vietnam and Colombia than in Switzerland, Austria, Denmark and Japan. Moreover, we note that the proportion of conditional cooperators varies across locations.

Table 2 shows p-values of pair-wise tests of the null hypothesis of equal distribution of contributor types across locations using Fisher's exact tests. For these comparisons we use our results from the no disclosure treatment in both countries. We first test whether the distribution of contributors is the same in Colombia and Vietnam, and find that we cannot reject the hypothesis. We then conduct tests to compare Colombia and Vietnam with the previous studies reported above. We find significant differences at the $5 \%$ level when we compare with the experiments in Switzerland and Japan, and in the case of Vietnam when compared with the U.S. When testing the null hypothesis of equal proportion of each contributor type across countries we cannot reject the null hypothesis for conditional cooperators and hump-shape contributors in any of the pair-wise comparisons between the findings from Colombia and Vietnam as well as between the two countries and the results reported in the other reported studies at the 5\% significance level, except when compare hump-shape contributors of Vietnam with Danes in Thöni et al. (2009) and Americans in 
Kocher et al. (2008). The proportions of free-riders in Colombia and Vietnam are similar in proportion to those found in Russia and the U.S., yet significantly different from the proportions found in Switzerland, Denmark, Austria, and Japan. Thus, overall the differences in the distribution of types can be explained by the differences in the proportion of free-riders.

Table 1. Distribution of contributor types.

\begin{tabular}{|c|c|c|c|c|c|c|c|c|c|c|}
\hline & \multicolumn{2}{|c|}{ Colombia } & \multicolumn{2}{|c|}{ Vietnam } & \multirow{3}{*}{$\begin{array}{c}\text { Switzerland } \\
\text { Fischbacher } \\
\text { et al. (2001) } \\
\text { No } \\
\text { Disclosure }\end{array}$} & \multirow{3}{*}{$\begin{array}{c}\text { Denmark } \\
\text { Thöni et } \\
\text { al. (2009) } \\
\text { No } \\
\text { Disclosure }\end{array}$} & \multirow{3}{*}{$\begin{array}{c}\text { Russia } \\
\\
\text { Herrmann } \\
\text { and Thöni } \\
\text { (2009) } \\
\text { No } \\
\text { Disclosure } \\
\end{array}$} & \multirow[t]{2}{*}{ U.S. } & \multirow{2}{*}{$\begin{array}{l}\text { Austria } \\
\text { her et al. (200 }\end{array}$} & \multirow{2}{*}{$\begin{array}{l}\text { Japan } \\
\text { 8) }\end{array}$} \\
\hline & \multicolumn{2}{|c|}{ The present study } & \multicolumn{2}{|c|}{ The present study } & & & & & & \\
\hline & $\begin{array}{c}\text { No } \\
\text { Disclosure }\end{array}$ & Disclosure & $\begin{array}{c}\text { No } \\
\text { Disclosure }\end{array}$ & Disclosure & & & & $\begin{array}{c}\text { No } \\
\text { Disclosure }\end{array}$ & $\begin{array}{c}\text { No } \\
\text { Disclosure }\end{array}$ & $\begin{array}{c}\text { No } \\
\text { Disclosure }\end{array}$ \\
\hline Free-rider & $4.2 \%$ & $12.5 \%$ & $4.2 \%$ & $4.2 \%$ & $29.6 \%$ & $13,9 \%$ & $6.3 \%$ & $8.3 \%$ & $22.2 \%$ & $36.1 \%$ \\
\hline $\begin{array}{l}\text { Conditional } \\
\text { cooperator }\end{array}$ & $62.5 \%$ & $75.0 \%$ & $50.0 \%$ & $58.3 \%$ & $50.0 \%$ & $70,2 \%$ & $55.6 \%$ & $80.6 \%$ & $44.4 \%$ & $41.7 \%$ \\
\hline $\begin{array}{l}\text { Hump- } \\
\text { shape }\end{array}$ & $8.3 \%$ & $6.3 \%$ & $8.3 \%$ & $14.6 \%$ & $13.6 \%$ & - & $7.5 \%$ & $0.0 \%$ & $11.1 \%$ & $11.1 \%$ \\
\hline Others & $25.0 \%$ & $6.3 \%$ & $37.5 \%$ & $22.9 \%$ & $6.8 \%$ & $15,9 \%$ & $30.6 \%$ & $11.1 \%$ & $22.2 \%$ & $11.1 \%$ \\
\hline $\begin{array}{l}\text { Number of } \\
\text { observations }\end{array}$ & 48 & 48 & 48 & 48 & 44 & 1070 & 160 & 36 & 36 & 36 \\
\hline
\end{tabular}

Note. In Thöni et al. (2009) hump-shaped type is classified as others (about one third of the subjects classified as others).

Table 2. Fisher's exact test of equal proportion of types in pair-wise comparisons (p-values).

\begin{tabular}{lccccccc}
\hline & $\begin{array}{c}\text { Colombia } \\
\text {-Vietnam }\end{array}$ & $\begin{array}{c}\text { Colombia- } \\
\text { Switzerland }\end{array}$ & $\begin{array}{c}\text { Colombia } \\
\text {-Russia }\end{array}$ & $\begin{array}{c}\text { Colombia - } \\
\text { Denmark }\end{array}$ & $\begin{array}{c}\text { Colombia } \\
\text {-U.S. }\end{array}$ & $\begin{array}{c}\text { Colombia } \\
\text {-Austria }\end{array}$ & $\begin{array}{c}\text { Colomb } \\
\text { ia-Japan }\end{array}$ \\
\hline Free-rider & $>0.99$ & $<0.01$ & 0.74 & 0.05 & 0.65 & 0.02 & $<0.01$ \\
Conditional & 0.30 & 0.29 & 0.41 & 0.26 & 0.09 & 0.12 & 0.08 \\
cooperator & & & & & & & \\
Hump-shape & $>0.99$ & 0.51 & 0.77 & $<0.01$ & 0.13 & 0.72 & 0.72 \\
Others & 0.27 & 0.02 & 0.59 & - & 0.16 & 0.80 & 0.16 \\
\hline Overall & 0.59 & $<0.01$ & 0.85 & - & 0.08 & 0.07 & $<0.01$ \\
\hline & & Vietnam- & Vietnam- & Vietnam - & Vietnam- & Vietnam- & Vietna \\
& & Switzerland & Russia & Denmark & U.S. & Austria & m- \\
\hline Free-rider & & $<0.01$ & 0.74 & 0.05 & 0.65 & 0.02 & $<0.01$ \\
Conditional & & $>0.99$ & 0.51 & $<0.01$ & 0.01 & 0.66 & 0.51 \\
cooperator & & 0.51 & 0.77 & $<0.01$ & 0.13 & 0.72 & 0.72 \\
Hump-shape & & $<0.01$ & 0.38 & - & 0.01 & 0.16 & 0.01 \\
Others & $<0.01$ & 0.82 & - & $<0.01$ & 0.06 & $<0.01$ \\
\hline Overall & & & & & & Japan \\
\hline
\end{tabular}

Note. In Thöni et al. (2009) hump-shaped type is classified as others.

The average unconditional contribution in the no-disclosure treatment is around $39.9 \%$ of the endowment in Colombia (7.98 tokens) and 25.8\% of the endowment in Vietnam (5.17 tokens). ${ }^{4}$ In the disclosure treatment, the average unconditional contribution is $48.1 \%$ of the

\footnotetext{
${ }^{4}$ We present more detailed descriptive statistics for each treatment and each type of contributor in Appendix.
} 
endowment in Colombia and 31.9\% in Vietnam. ${ }^{5}$ We observe a similar absolute increase in unconditional contributions in percentage points in both countries: around 8.2 percentage points in Colombia and 6.1 percentage points in Vietnam. As shown in Figure 2, introducing disclosure in the Colombian case results in an increase in the proportion of subjects contributing the whole endowment, while in Vietnam there is a shift from a large fraction of contributions below $50 \%$ of the endowment to a spike at an unconditional contribution of $50 \%$ of the endowment. In an overall test for the null hypothesis of equal distributions of unconditional contributions in the no-disclosure and disclosure treatments, we cannot reject the hypothesis for either country ( $p$-value $=0.24$ for Columbia and $p$-value $=0.08$ for Vietnam) based on the Wilcoxon-Mann-Whitney test. Using this test for the null hypothesis of equal distributions of guessed average unconditional contribution by others, we also cannot reject the hypothesis of equal distributions for both Colombia and Vietnam (p-value is equal to 0.73 and 0.67 , respectively).

Figure 2. Histograms of unconditional contributions per treatment

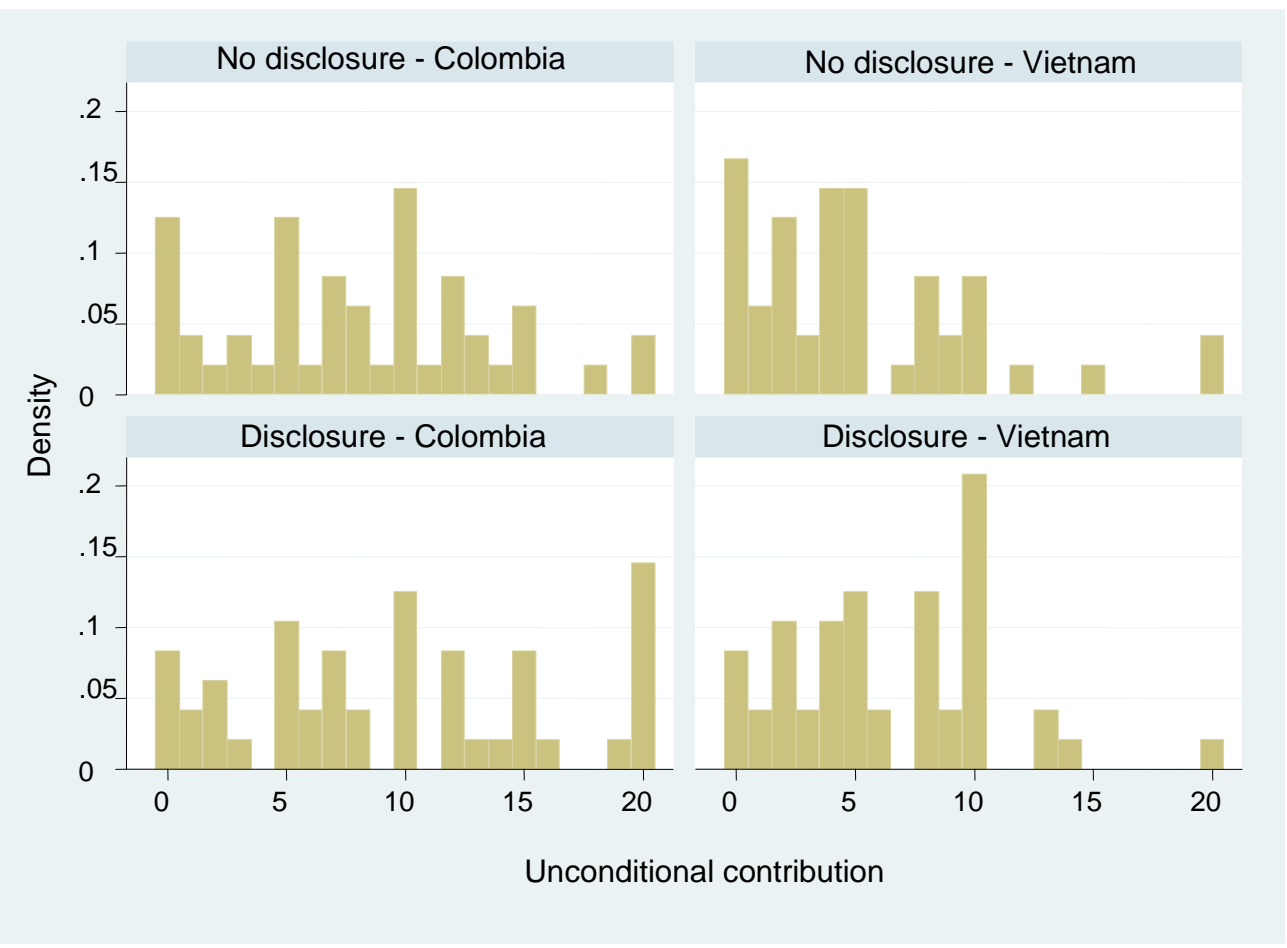

\footnotetext{
${ }^{5}$ A related issue is whether the unconditional contributions of subjects of a specific contribution type have been affected by the disclosure treatment. To test the null hypothesis of no effect on unconditional contribution between treatments among subjects classified as one specific type of contributor, we conducted a WilcoxonMann-Whitney test. Since we classified subjects into four types in two countries, we conducted eight tests. We could not reject the hypothesis of no difference in unconditional contribution between the treatments in any of the eight tests.
} 


\section{Discussion}

This paper has investigated whether the distribution of contribution types in public goods experiments is robust across locations and when behavior is disclosed based on the experimental design developed by Fischbacher et al. (2001). The two countries included in our study - Colombia and Vietnam - have a very low degree of individualism when using the Hofstede scale compared with other countries where the Fischbacher et al. (2001) design has been applied. The results show conditional cooperator is the dominating type across locations similar to the results in other studies, but the proportion of them varies. Contrary, the proportion of free-riders differs significantly ly when compared with other studies. This paper also compares the effect of disclosure and the overall results suggest that disclosure has a small impact on contributions to public goods.

The small increase in contributions when disclosure is introduced is different from the stronger influences of other institutions such as monetary punishment (e.g., Fehr and Gächter, 2000; Herrmann et al., 2008). ${ }^{6}$ It should however be noted that previous findings on the effect of introducing disclosure on contributions are mixed (e.g., Rege and Telle, 2004; Noussair and Tucker, 2007). The small positive effect from disclosure may indicate either that the image motivation to increase contribution level when subject to disclosure is small or the net effect of image and intrinsic motivations is small. A detailed analyses show that distribution of types is stable across our treatments. Thus, given that different institutions such as monetary punishment (e.g., Fehr and Gächter, 2000), social disapproval (e.g., Masclet et al., 2003), exclusion (e.g., Cinyabuguma et al., 2005; Maier-Rigaud et al., 2010) and disclosure have different impact on individuals' behaviour, it seems important to better understand the impact on the distribution of contribution types. Thus, we need to better understand why some individuals who are classified as one specific contribution type in a standard public goods experiment behave differently when certain institutions are introduced, or, in other words, what makes it worthwhile for them to change, and to be able to explain these changes by motivations. A related issue, Gächter et al. (2010) show in the monetary

\footnotetext{
${ }^{6}$ Although monetary punishment has been shown to increase contributions, the overall effect on welfare tends to be negative in earlier periods. However, in a 50 period public goods experiment with monetary punishment, Gächter et al. (2008) find positive and significant welfare effects. In contrast, disclosure does not incur any monetary costs.
} 
punishment case that differences in contributions are, to an important degree, determined by cultural differences, and thus culture should also be one of the focuses in this field of research. In our case, intrinsic motivation and image motivations in Vietman and Colombia can be represented by the degree of individualism according to the Hofstede scale. Colombia and Vietnam have a very low degree of individualism when using the Hofstede scale, and thus the small effect of disclosure might then be explained by the degree of collectivism in both countries. Needless to say, future research is needed to investigate the roots of cooperation, where understanding of the role of different types of motivations is needed, to be able to better understand observed differences in contributions to public goods in various circumstances. 


\section{References}

Ariely, D., Bracha, A., Meier, S., 2009. Doing Good or Doing Well? Image Motivation and Monetary Incentives in Behaving Prosocially. American Economic Review 99, 544-555.

Benabou, R., Tirole, J., 2006. Incentives and Prosocial behavior. American Economic Review 96, 1652-1678.

Brandts, J., Charness, G., 2011. The strategy versus the direct-response method: a first survey of experimental comparisons. Experimental Economics 14, 375-398.

Carpenter, J., Daniere, G., Takahashi, L., 2004. Cooperation, Trust, and Social Capital in Southeast Asian Urban Slums. Journal of Economic Behavior and Organization 55, 533-551.

Chaudhuri, A., 2011. Sustaining cooperation in laboratory public goods experiments: a selective survey of the literature. Experimental Economics 14, 47-83.

Cinyabuguma, M., Page, T., Putterman, L., 2005. Cooperation under the Threat of Expulsion in a Public Goods Experiment. Journal of Public Economics 89, 1421-1435.

Fehr, E., Gächter, S., 2000. Cooperation and Punishment in Public Goods Experiments. American Economic Review 90, 980-994.

Fischbacher, U., Gächter, S., 2010. Social preferences, beliefs and the dynamics of free riding in public good experiments. American Economic Review 100, 541-556.

Fischbacher, U., Gächter, S., Fehr, E., 2001. "Are People Conditionally Cooperative? Evidence from a Public Goods Experiment." Economics Letters 71, 397-404.

Gächter, S., Herrmann, B., Thöni, C., 2010. Culture and cooperation. Philosophical Transactions of the Royal Society B 365, 2651-2661.

Gächter, S., Renner, E., 2010. The effects of (incentivized) belief elicitation in public good experiments. Experimental Economics 13, 364-377.

Gächter, S., Renner, E., Sefton, M., 2008. The Long-Run Benefits of Punishment. Science 322, 1510.

Herrmann, B., Thöni, C., 2009. Measuring conditional cooperation: A replication study in Russia. Experimental Economics 12, 87-92.

Herrmann, B., Thöni, C., Gächter, S., 2008. Anti-Social Punishment across Societies. Science 319, 1362-1367.

Hofstede, G., 2001. Culture's Consequences, Comparing Values, Behaviors, Institutions, and Organizations Across Nations. Thousand Oaks CA: Sage Publications.

Inglehart, R., Baker W.E., 2000. Modernization, cultural change, and the persistence of traditional values, American Sociological Review 65, 19-51. 
Kelley, H., Stahelski, A., 1970. Social Interaction Basis of Cooperators' and Competitors' Beliefs About Others. Journal of Personality and Social Psychology 16, 190-219.

Keser, C., van Winden, F., 2000. Conditional Cooperation and Voluntary Contributions to Public Goods. Scandinavian Journal of Economics 102, 23-39.

Kocher, M., Cherry, T. Kroll, S., Netzer, R., Sutter, M., 2008. Conditional cooperation on three continents. Economic Letters 101, 175-178.

Ledyard, J., 1995. Public goods: A survey of experimental research in Kagel, J. and A. Toth (eds.), Handbook of Experimental Economics, Princeton University Press, Princeton, NJ.

Maier-Rigaud, F.P., Martinsson, P., Staffiero, G., 2010. Ostracism and the provision of a public good: Experimental Evidence, Journal of Economic Behavior and Organization 73, 387-395.

Markus, H. R., Kitayama, S., 1991. Culture and the self: Implications for cognition, emotion, and motivation. Psychological Review 98, 224-253.

Masclet, D., Noussair, C., Tucker, S., Villeval, M., 2003. Monetary and Non-Monetary Punishment in the Voluntary Contributions Mechanism. American Economic Review 93, 366-380.

Noussair, C., Tucker, S., 2007. Public observability of decisions and voluntary contributions in a multiperiod context. Public Finance Review 35, 176-198.

Rege, M., Telle, K., 2004. The impact of Social Approval and Framing on Cooperation in Public Good Situations. Journal of Public Economics 88, 1625-1644.

Soetevent, A.R., 2005. Anonymity in giving in a natural context: An economic field experiment in thirty churches. Journal of Public Economics 89, 2301-2323.

Thöni, C., Tyran, J.-R., Wengström E., 2009, Microfoundations of social capital. Discussion paper 09-24, Department of Economics, University of Copenhagen.

Thoumi, F., 2009. Necessary, sufficient and contributory factors generating illegal economic activity, and specifically drug-related activity, in Colombia. Iberoamericana 35, 105126.

Zelmer, J., 2003. Linear public goods experiments: A meta-analysis. Experimental Economics 6, 299-310. 
Appendix. Distribution of contributor types - detailed descriptive statistics.

\begin{tabular}{|c|c|c|c|c|c|c|c|c|c|c|c|c|}
\hline & \multicolumn{6}{|c|}{ Colombia } & \multicolumn{6}{|c|}{ Vietnam } \\
\hline & \multicolumn{6}{|c|}{ The present study } & \multicolumn{6}{|c|}{ The present study } \\
\hline & & No Disclosur & & & Disclosure & & & No Disclosure & & & Disclosure & \\
\hline & Dist. & $\begin{array}{l}\text { Avg. } \\
\text { Uncond. } \\
\text { Cont. }\end{array}$ & $\begin{array}{c}\text { Guess Avg. } \\
\text { Uncond. } \\
\text { Cont. }\end{array}$ & Dist. & $\begin{array}{l}\text { Avg. } \\
\text { Uncond. } \\
\text { Cont. }\end{array}$ & $\begin{array}{c}\text { Guess Avg. } \\
\text { Uncond. } \\
\text { Cont. }\end{array}$ & Dist. & $\begin{array}{l}\text { Avg. } \\
\text { Uncond. } \\
\text { Cont. }\end{array}$ & $\begin{array}{c}\text { Guess Avg. } \\
\text { Uncond. } \\
\text { Cont }\end{array}$ & Dist. & $\begin{array}{l}\text { Avg. } \\
\text { Uncond. } \\
\text { Cont. }\end{array}$ & $\begin{array}{c}\text { Guess Avg. } \\
\text { Uncond. } \\
\text { Cont }\end{array}$ \\
\hline Free-rider & $4.2 \%$ & 0.5 & 2.00 & $12.5 \%$ & 0.7 & 3.5 & $4.2 \%$ & 10.0 & 10.0 & $4.2 \%$ & 0.5 & 0.7 \\
\hline \multirow{2}{*}{$\begin{array}{l}\text { Conditional cooperator } \\
\text { Hump- shape }\end{array}$} & $62.5 \%$ & 9.3 & 9.5 & $75.0 \%$ & 11.6 & 10.2 & $50.0 \%$ & 5.5 & 6.4 & $58.3 \%$ & 7.4 & 7.0 \\
\hline & $8.3 \%$ & 8.8 & 8.3 & $6.3 \%$ & 6.7 & 8.2 & $8.3 \%$ & 1.5 & 5.9 & $14.6 \%$ & 5.1 & 5.2 \\
\hline Others & $25.0 \%$ & 5.6 & 6.2 & $6.3 \%$ & 7.0 & 3.4 & $37.5 \%$ & 5.1 & 5.8 & $22.9 \%$ & 5.6 & 6.3 \\
\hline Number of observations & & 48 & & & 48 & & & 48 & & & 48 & \\
\hline
\end{tabular}

Note. Dist.: Distribution. Avg. uncond. cont.: average unconditional contribution. Guess avg. uncond. cont.: guessed average unconditional contribution. 